\title{
Evidencia inca en el sitio arqueológico Chukurpus. Cuenca alta del río Ica
}

\section{Inca evidence at the Chukurpus archaeological site. Upper basin of the Ica river}

\author{
José Luis Quispe Orosco \\ https://orcid.org/0000-0002-3153-6794 \\ Instituto de Paleontología y Medio Ambiente - IPAMA \\ arqueorosco@hotmail.com \\ Marco Taquiri González \\ https://orcid.org/o0oo-0002-0372-3648 \\ Instituto de Paleontología y Medio Ambiente - IPAMA \\ marco.takiri@gmail.com

\section{Carls W. Chuquihuaccha Huancahuari} \\ https://orcid.org/0000-0002-2355-9937 \\ Instituto de Paleontología y Medio Ambiente - IPAMA \\ carls.ch.h@gmail.com
}

\section{RESUMEN}

En el presente artículo explicamos de manera sintetizada parte del proceso cultural prehispánico de la cuenca alta del río Ica, con mayor énfasis tratamos el Período Intermedio Tardío (chukurpus) y Horizonte Tardío (Inca) (1100 d. C.-1532 d. C.). Precisamos los tópicos y evidencias para determinar cambios en cada época a través del correlato material. Los elementos culturales, bienes muebles e inmuebles, y los métodos para la acumulación de los datos empíricos, fueron los instrumentos de investigación para definir la diversidad de manifestaciones culturales, expuestas durante la excavación arqueológica en el Sitio Arqueológico Chukurpus.

Palabras clave: Chukurpus; cuenca alta; Inca; río Ica. 


\section{ABSTRACT}

In this article we explain in a synthesized way part of the pre-Hispanic cultural process of the upper basin of the Ica river, with greater emphasis we treat the Late Intermediate Period (chukurpus) and Late Horizon (Inca) (1100 AD - 1532 AD). We specify the topics and evidence to determine changes in each period through the material correlate. The cultural elements, movable and immovable property, and the methods for the accumulation of empirical data, were the research instruments to define the diversity of cultural manifestations, exposed during the archaeological excavation at the Chukurpus Archaeological Site.

Keywords: Chukurpus; upper basin; Inca; río Ica.

ReCibidO: 24/09/2018 - ACePTADO: 16/09/2020 - PublicAdo: 25/06/2021

\section{INTRODUCCIÓN}

Por lo general los estudios incas versan sobre las urbes de arquitectura imperial, o en sitios adyacentes al Qhapaq Ñan, en ese contexto la literatura resulta limitada cuando se requiere investigar el impacto inca en las zonas alejadas a los centros regionales. Al momento de la anexión de los Incas, los rukanas, angaraes y chukurpus estaban organizados como una serie de grandes entidades políticas rivales, las múltiples lenguas y divisiones culturales descritas por Monzón (1881[1586], p. 182) pueden reflejar esta división política.

Los chukurpus ocuparon los drenajes superiores de la cuenca del río Ica y controlaron las extensiones circundantes de puna, incluyendo los valles interandinos de la cuenca superior del río Pampas (Ayacucho). Los valles y quebradas, superior y medio del río Ica, separados físicamente por una constricción de paredes empinadas, tienen grandes poblados y variados asentamientos pequeños como el sitio Chukurpus, un poblado tardío, previamente existente a la anexión Inca.

Hasta ahora la investigación sugiere que los chukurpus formaron parte de una anexión temprana en la construcción del Imperio, donde funcionarios incas se desplegaron en toda la región, tomando zonas estratégicas de ubicación y producción. Esto podría explicar la presencia de materiales inca en el sitio. Nuestras investigaciones han revelado la presencia de elementos intrusivos inca. En esta época Huaytará fue instalado como un centro administrativo regional, posicionado a lo largo de un sistema de caminos reales, y conectado a una jerarquía administrativa de sitios menores, como el caso del sitio Chukurpus.

El objetivo fue examinar los mecanismos de anexión inca en Chukurpus, a través del estudio de los materiales hallados durante la excavación. La estratégica ubicación del Sitio Arqueológico Chukurpus en una quebrada temperada altamente productora de maíz puede haber resultado en ungrado de inversión inca más alto de lo esperado en la región. 


\section{EL ESPACIO GEOGRÁFICO E HISTÓRICO}

\subsection{El escenario ecológico}

El territorio ocupado por los chukurpus está ubicado en la actual región de Huancavelica, esta zona comprende el curso superior del río Pampas y el drenaje superior del río Ica. Dicho territorio abarca un área de sorprendente diversidad ecológica en la sierra surcentral. Debido a los cambios espaciales abruptos de altitud, el área de estudio abarca varias zonas ecológicas. Para el presente trabajo esta diversidad se puede sintetizar en tres (03) franjas ecológicas: las cabezadas (wayqu runakuna), la altiplanicie (sallqa runakuna) y los valles interandinos (kisua runakuna). Las cabezadas abarcan la zona yunga y quechua de la vertiente occidental de los Andes centrales; la altiplanicie corresponde a los pastizales intramontanos de las punas y la gélida Cordillera; y los valles interandinos corresponden a las quebradas y valles del drenaje alto del río Pampas. Estas zonas componen parte de las ocho regiones naturales definidas por Pulgar Vidal (1996): yunga (valles cálidos en la vertiente oriental de los Andes, 500-2400 m s. n. m.), quechua (zona montañosa atravesada por valles y quebradas $2400-3500 \mathrm{~m} \mathrm{s.} \mathrm{n.} \mathrm{m.),} \mathrm{suni} \mathrm{(montañas} \mathrm{onduladas} \mathrm{de} \mathrm{valles} \mathrm{y} \mathrm{cadenas}$ escarpadas 3500-4000 m s. n. m.) y puna (altiplanicie, 4000-4800 m s. n. m.).

El poblado prehispánico de Chukurpus se ubica a 3100 metros de altitud, en la zona de vida Estepa-Montano Tropical, que se distribuye a lo largo del flanco occidental andino (ONERN, 1976, p. 87), área que corresponde a la serranía esteparia (SIGMINAN 2011: Mapa- $\mathrm{N}^{\circ} 53$ ), que se extiende en el declive oriental de la región quechua: «Valles y quebradas que trepan al Ande» (Pulgar Vidal, 1996, p. 23), en clara alusión a la zona descrita como cabezada (ver figura 01).

\subsection{Informaciones etnohistóricas}

Las fuentes documentales ofrecen breves descripciones sobre los chukurpus, estos datos han sido recopilados de las crónicas, y de las visitas y relaciones coloniales de la segunda mitad del siglo XVI. Estos documentos ofrecen información detallada sobre la ecología andina, las características físicas del territorio, las posibilidades económicas de la región y los mecanismos de anexión inca de las entidades tardías.

Pedro Cieza de León (1880 [1553]). En La Crónica del Perú. Segunda Parte, relata que Pachacútec después de vencer a los chankas mando una expedición de su ejército al valle de Xauxa. Los incas motivados por razones económicas priorizaron la incorporación de las etnias del área central, Pachacútec, el noveno inca llevó a cabo este objetivo. Este inca, al tomar el mando del Cusco alrededor de 1438 incorporó a las diferentes etnias de la región de Ayacucho y Huancavelica, utilizando distintos mecanismos de incorporación, entre ellos la diplomacia y la persuasión:

«Y como se hobiesen holgado los días que les parecio a Inca Yupanqui [Pachacútec], les hablo como quería que fuesen a los Guancas, y a los Yauyos, 


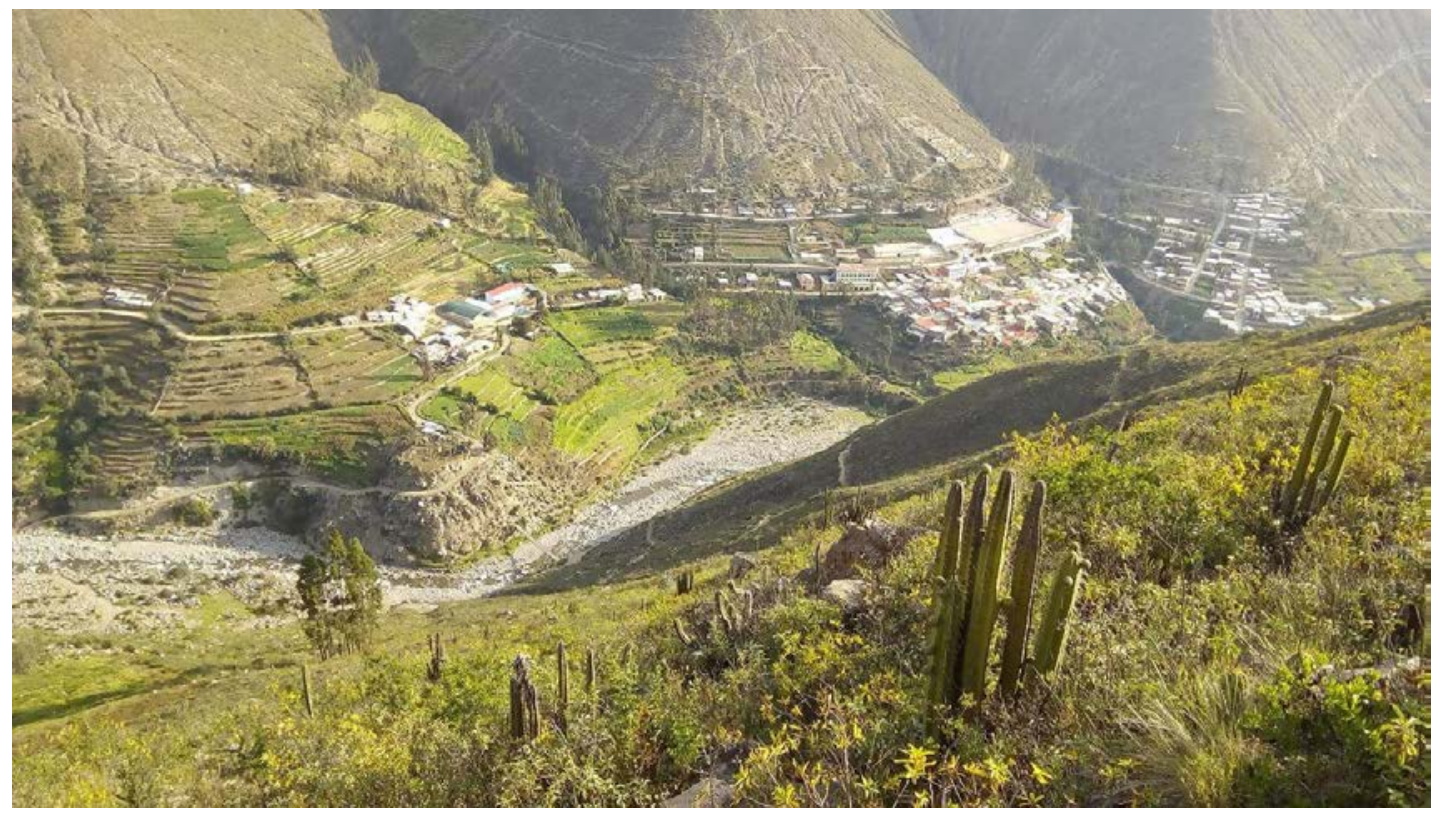

Figura 01. Geografía de las cabezadas en el drenaje superior del valle de Ica. Cuenca del río Santiago, tributario del río Ica. Derecha superior: Distrito de Santiago de Chocorvos, vista desde el sitio arqueológico Chukurpus. Foto de Marco A. Taquiri.

sus vecinos [los chocorbos], y procurar de los traer en su amistad y servicio sin guerra, y cuando nó, que, dándosela, se diesen maña de los vencer y forzar que lo hiciesen» (p. 178-184: Cap. XLVII y Cap. XLIX).

En otros casos la represión coercitiva fue parte de la conquista inca, la guerra que tuvo contra los soras es un ejemplo claro:

«El rey [...] determinó de ir a los Soras. Y saliendo de allí, anduvo por un despoblado que iba a salir a los Soras, los cuales supieron su venida y se juntaron para se defender. Había enviado Inga Yupangue capitanes con gente por otras partes muchas a que allegasen las gentes a su servicio con la más blandura que pudiesen y a los soras envió mensajeros sobre que no tomasen armas contra él, prometiendo de los tener en mucho sin les hacer agravio ni daño; mas no quisieron paz con servidumbre sino guerrear por no perder la libertad. Y así, juntos unos con otros tuvieron la batalla, la cual, dicen los que tienen de ello memoria, que fue muy reñida y que murieron muchos de ambas partes, mas quedando el campo por los del Cuzco» (pp. 178-184: Cap. XLVII y Cap. XLIX).

Damián de la Bandera (1968 [1557]). El relato indica que existían una jerarquía de curacazgos que mantenían constante guerra por el control de enclaves estratégicos, motivo por el cual habitaban la cima de los cerros y vivían en una atmósfera 
de guerra inminente, uno de los curacas fue el Asto Capac, los chocorbos del drenaje superior del río Ica formaban parte de su área de influencia: «Y otro senor que hubo en los chocorbos, que se llamaba Asto Capac, que senoreo mucha tierra». (p. 491)

Hernando de Santillán (1968 [1563]). Santillán ofrece una relación de los tributos que entregaban los curacas de cada provincia en tiempos de su gentilidad al Estado inca, el curaca que sujetaba los valles y provincias al norte de los rukanas fue el Asto Capac, que fueron anexados tempranamente por el inca Pachacútec: «Y otro senor hubo en los Chocorvos que se llamó Hasto Capac, y enseñoreo ciertas provincias comarcanas; pero esto era en particular, pero en general ninguno se apodero ni redujo la tierra a modo de reino e imperio hasta que comenzaron a reinar los ingas $»^{1}$ (p. 101).

Cristóbal de Albornoz (en Duviols 1967 [1584]). Cristóbal de Albornoz en 1570 visita a los antiguos territorios del obispado del Cusco en el proceso de extirpación de idolatrías, con el fin eliminar el culto idolátrico a lo largo de los Andes. La extensión territorial del obispado de Cuzco antes de 1570 comprendía los territorios actuales de Cusco, Apurímac, Ayacucho y Huancavelica. En este proceso registró las principales huacas de la provincia de los angaraes y chocorbos:

«Sasaylla apo, guaca de las muy principales del reino. Es una cueva detrás del pueblo de Parcos, en una ladera.

Carcanicho, guaca de los indios angaraes, es un cerro frontero del pueblo de Paucararay.

Socla, guaca de los indios pariscas de Diego Gavilan. Es un cerro nevado junto al pueblo Paucarbamba.

Choclo cacha [Choclococha], laguna grande en la puna de Guaytara, de grande beneracion, que nascen della ríos, y le hazían muchos sacrificios.

En estas provincias [Angaraes y Chocorbos], visitándolos yo, hallé muy muchas guacas y camayos dellas y deshize muchas dellas, y otras quemé, y quedó orden y memoria en los libros que hize de fábricas, con el aviso que pude» (Duviols, 1967, p. 29).

Diego Dávila Brizeño (1881[1586]). En 1586 Diego Davila Brizeño, corregidor de la provincia de los yauyos realiza una visita a los territorios que formaban parte de esta provincia, describe sus límites territoriales, los pequeños pueblos habitados en riscos y fuertes, y las guerras que los yauyos tenían con las etnias vecinas, quedando los chocorbos a la parte sur:

«[...] Y con la provincia de los Chocorbos, que le caen a la parte del Sur. Por que con todas estas dichas provincias tenían guerras en su gentilidad». En

\footnotetext{
1. Los dominios del señor principal Asto Capac cubría una gran extensión territorial: ocupaba la sierra central de Huancavelica, específicamente los valles interandinos y afluentes del río Mantaro. Además, los chocorbos habitaban los afluentes del curso superior del río Pampas, provincia de Ayacucho, y parte de estos grupos se extendían por las cabezadas del valle de Ica. Los Astos junto con Chakak fueron parcialidades de una provincia grande denominada los Angaraes, que ocupaban la parte central de Huancavelica (Lavallée y Julien, 1983).
} 
tiempo inca los yauyos especializados en la crianza de camélidos, explotaban las tierras altas de los chocorbos: «Aunque en esta dicha provincia [Yauyos], por tener pocos pastos, le dieron los Ingas en la de los Chocorbos, que la linda la parte del Sur, a cada guaranga un pedazo de pasto, que hoy poseen y tienen» (pp. 61, 78).

Garcilaso de la Vega (1945 [1609]). El cronista describe el desplazamiento de las tropas de Pachacútec en la sierra central, la gran expedición estaba dirigida a la conquista de los huancas y xauxas, anexando a su paso la provincia de Chukurpus: «Acordaron que el Inca volviese a la conquista [...]. Apercibieron cincuenta mil hombres de guerra. Los incas salieron con el primer tercio; caminando hasta la gran provincia llamada Chucurpu, que era la última del Imperio por aquel paraje» (pp. 32 capítulo XII LIBRO SEXTO).

Santa Cruz Pachacuti (1993 [1613]). El fragmento indica que Pachacutec, luego de la conquista de los chankas de Andahuaylas incursionó en dirección norte anexando las etnias que formaban parte de la Confederación Chanka; entre ellos los chukurpus: «Y en el entretanto el dicho Pachacuti Ynga Yupangui les conquista a toda la provincia de los Angaraes y Chilquiorpus [chukurpus] y Lucaras y Soras» (p. 222).

\subsection{La anexión de los chukurpus al Estado inca}

Consideramos que la anexión de los chukurpus al Imperio inca fueron por razones económicas y políticas, esta etnia ocupaba un vasto territorio, poseía tierras maiceras en las cabezadas, área colindante con el valle de Ica, además de andenerías en los valles del curso superior del río Pampas, en la actual provincia de Cangallo (Ayacucho). Las punas ganaderas, de abundantes pastizales se extendían en la altiplanicie, situado entre ambos ríos. Estos territorios se hallaban bajo el control de un curaca importante, de prestigio político, y administrativo regional, el Asto Capac. La distribución étnica de los chukurpus en la cuenca superior del río Pampas está documentado por la Revisita de los Chocorbos realizado en 1683: «Los chocorbos originalmente se asentaron en Huancavelica osea en territorio de la nación Angaraes y que posteriormente fueron trasladados hacia la provincia de Víctor Fajardo donde se realizara la revisita» (Huertas et al., 1976, p. 161).

La etnia chukurpus fue incorporado tempranamente al Estado inca bajo el gobierno de Cusi Inga Yupanqui o Pachacutec, aproximadamente hacia 1438 d. C. (Santillana, 2012, p. 79). La anexión pacifica con énfasis en la diplomacia y la persuasión, fueron los mecanismos que utilizaron los incas para incorporar a las etnias que formaban parte de la Confederación Chanka, un fragmento de Damián de la Bandera (1968[1557], p. 491), indica con claridad los arreglos de Pachacutec para anexionar estos territorios:

«El primer Inga que comenzó a conquistar se llamó Inga Yupanqui [Pachacutec], y el modo con que comenzó y siempre guardo es de advertir que fue desta manera: que, en llegando a una provincia, enviaba sus mensajeros diciendo que ni pretendía ninguna cosa más de los tener en razón y defenderles de 
quien mal les hiciese». De esta forma permitía a los curacas tener beneficios y recompensas, los objetos suntuarios se entregaban como parte de la reciprocidad estatal: «Y como era hijo del sol y que él [Inca], le enviaba, y les venía dar y hacer mercedes; $y$ ansi, a todos los señores que le salían de paz hacia mercedes, [...] y él les daba vasos de oro y ropa la del Cuzco» (ibíd. 1968 [1557], p. 491).

Con la finalidad de repotenciar las actividades productivas de la zona quechua fueron trasladadas diversos grupos de mitimaes que provenían del centro y sur. Estos grupos étnicos fueron ubicados en diferentes partes del territorio huancavelicano, por ejemplo, en los valles interandinos de la provincia de Angaraes fueron establecidos los chankas de Andahuaylas, guaros de Huarochiri y los caxamarcas en condición de mitimaes (ver tabla 1). Las quebradas de los ríos Olaya y Santiago, tributarios del río Ica, han sufrido grandes alteraciones con el impacto inca, el paisaje ha sido transformado completamente, la construcción de los andenes de depurada técnica y los canales de regadío que los alimentan testimonian la alta productividad maicera de esta zona. Así mismo, esta zona produce ajíes y frutales, trocados en el tráfico de intercambio a nivel comunal y estatal en tiempos inca: «Por la mayor parte [del poniente] es templada; en que se da maíz y trigo, y tiene muchos [parajes] calientes en que se dan diversas frutas y alguna caña» (Ribera y Chávez de Guevara, 1881[1586], p. 140).

Tabla 1

Descripción de la Provincia de los Angaraes - Huancavelica

\begin{tabular}{|c|c|c|c|}
\hline DOCTRINA & PUEBLOS & GRUPOS LOCALES & MITIMAES \\
\hline \multirow[t]{3}{*}{ LIRCAY } & $\begin{array}{l}\text { Lircay, Uchuguayllay, } \\
\text { Angaraes, Atunguayllay }\end{array}$ & - & Chankas de Andahuaylas \\
\hline & Guanca Guanca & - & Chankas de Andahuaylas \\
\hline & Callanmarca & - & Caxamarca \\
\hline \multirow[t]{2}{*}{ JULCAMARCA } & Congalla & - & Chankas de Andahuaylas \\
\hline & Julcamarca & - & Chancas de Andahuaylas \\
\hline \multirow[t]{4}{*}{ ACOBAMBA } & Caja Espíritu Santo & $1 / 2$ Angaraes & $1 / 2$ Quiguares [Cusco] \\
\hline & Acombaba & - & Guaros [Huarochirí] \\
\hline & Todos Santos & - & Guaros [Huarochirí] \\
\hline & Andabamba & - & Guaros [Huarochirí] \\
\hline CONAICA & $\begin{array}{l}\text { Cuenca, Moya, } \\
\text { Vilcabamba, Conaica }\end{array}$ & Angaraes [Asto] & \\
\hline ACORIA & $\begin{array}{l}\text { Añacuci, Pallalla, } \\
\text { Chupaca, Acoria, Guando }\end{array}$ & Angaraes [Chacac] & \\
\hline
\end{tabular}

Nota: La visita de los vecinos de Huamanga Pedro de Ribera y Antonio de Chaves de 1586, enumera las doctrinas de Angaraes con presencia de mitimaes y grupos locales. (Adaptado de Urrutia, 2014). 
Tras su incorporación al Estado inca, la provincia de Angaraes y Chukurpus, fueron parcialmente alterados. La descripción de 1586 señala como estas provincias fueron despobladas de sus habitantes originarios, colocándose en reemplazo grupos de mitimaes provenientes de lugares distantes. Estos territorios, política y administrativamente se incorporaron a la provincia administrativa de Huaytará, tal cómo fueron hallados por los españoles durante su arribo a esta región (Carrasco, 2007, p. 129).

\subsection{Antecedentes de estudios arqueológicos}

Las exploraciones pioneras en Chocorvos las inició el Doctor Julio C. Tello y su equipo en 1941. La expedición de Chocorvos fue sistemática iniciándose entre Pisco y Huaytará pasando por Tambo donde registraron edificios incas. Entre Capillas, Santiago de Chocorvos y Córdova registraron poblados tardíos que ocupaban la cima de los cerros más altos, con típicas construcciones circulares. El sitio Aukimarca en Córdova presenta cerámica chincha, esta información es valiosa pues las exploraciones de González Carré en la cuenca del río Pampas (Cangallo-Ayacucho) también informan la presencia de fragmentos de cerámica chincha (Huertas et al., 1976). Esto demuestra la distribución de la cerámica chincha en una amplia región de los chukurpus, donde la alfarería arqalla del Período Intermedio Tardío es el estilo predominante.

Las investigaciones arqueológicas en Huancavelica son limitados y se han desarrollado con mayor énfasis en la parte septentrional del departamento: De acuerdo a Rodríguez (2016), se tiene el siguiente panorama:

Algunas de las investigaciones pioneras en la región (Ladrón de Guevara, 1959; Lumbreras, 1959a, 1959b, 1969; Matos, 1958, 1959a, 1959b, 1960; Ruiz, 1977) (p. 24). Todas estas investigaciones de acuerdo al autor citado, han revelado que, para el Intermedio Tardío, tenemos un panorama arqueológico en Huancavelica similar al registrado en regiones cercanas y en el resto de los Andes Centrales (para comparaciones ver Bauer y Kellet, 2010; Bauer et al., 2013; Covey, 2008; Parsons et al., 2004; Thompson, 1972). (p.24)

Se aprecia también que la mayoría de los asentamientos tienden a ocupar las partes altas o las laderas en las zonas de montaña, así, por ejemplo, señala Rodríguez (2016) que los asentamientos se registran entre los 3000 y 4000 metros de altitud.

El autor citado señala que estos asentamientos presentan una falta aparente de planeamiento en su disposición, sin embargo, en muchos casos están protegidos por grandes extensiones de murallas. Las residencias al interior de los sitios se disponen de manera aglutinada y forman series de conjuntos domésticos del tipo casa-patio, construidas sobre terrazas artificiales y articuladas por medio de corredores (Rodríguez, 2016, p. 24).

Esta regularidad tipológica de poblados erigidos sobre terrazas es semejante entre Huancavelica y el territorio ayacuchano, los asentamientos están comunicados por estrechas rutas de circulación (González Carré et al. 1987; González Carré 1992; Valdez y Vivanco 1994). De la misma forma, en los sitios tardíos de Huancavelica, están ausentes la complejidad arquitectónica pública y religiosa:

Los trabajos previos también describen una notoria falta de arquitectura pública-cívica o ceremonial-religiosa (Lavallée 1973; Lavallée y Julien 1983). 
De igual manera y, en contraste con los asentamientos registrados en Jauja (D'altroy y Hastorf, 2001), no se presentan datos claros sobre la existencia de diferencias en la calidad arquitectónica de las estructuras que puedan reflejar la existencia de grupos de élites y de no-élites. (Rodríguez, 2016, p. 25)

En cuanto a los trabajos sistemáticos de investigación con excavaciones en el departamento de Huancavelica desde la década de 1970 a la actualidad, se mantiene el siguiente escenario:

Los trabajos seminales de Lavallée (1973) y luego junto con Julien (1983) son los únicos ejemplos de excavaciones en múltiples sitios y con énfasis en la unidad doméstica que se han dado en el departamento de Huancavelica. Este proyecto pluridisciplinario buscaba, entre otras cosas, reconstruir la vida social-económica de los habitantes del señorío de los Asto (Provincia de Huancavelica) a través del estudio de las unidades domésticas y su equipo tecnológico, así como evaluar el impacto que la ocupación inca tuvo en la zona. (Rodríguez, 2016, p. 26-27)

Las investigaciones científicas en el dren superior del río Ica son escasas, una de las recientes investigaciones se realizó en la sub cuenca del río Olaya, entre Challaca y Sangayaico, que demuestra la presencia temprana de los grupos costeños (nasca) en las tierras altas del valle de Ica (Lane et al. 2017).

En cuanto a la cerámica para el periodo Intermedio Tardío y Horizonte Inca de Huancavelica se tiene:

De manera general, existen dos estilos notables durante el Intermedio Tardío: el estilo coras definido por Matos $(1958,1959)$ en la Provincia de Huancavelica y el estilo Arqalla o Pataraqay registrado tanto en la provincia de Castrovirreyna como alrededor de la laguna de Choclococha y que ha sido usualmente asociado a cerámica Inca y contextos funerarios (Lumbreras, 1959a, 1959b; Matos, 1959a, 1960). Estos estilos cerámicos son de acabado simple y manufactura burda, las decoraciones tienden a ser simples líneas de colores crema, rojo, blanco o negro y en algunos casos existe decoración en apliques o cara gollete. Por otro lado, las formas más comunes son de cantaros globulares, ollas y en general "formas domésticas". (Rodríguez, 2016, p. 25-26).

\subsection{El Sitio Arqueológico Chukurpus.}

El sitio Chukurpus se encuentra ubicado a 2980 metros de altitud, al noroeste del distrito de Santiago de Chocorvos, Huancavelica. El poblado fue construido sobre la cima y ladera del cerro Chukurpus en un triángulo elevado formado por los ríos Olaya y Santiago, ríos que unen (tinkuy) sus aguas para tributar al río Ica. El sitio esta circundado por el lado sur por una fuerte pendiente vertical que brinda una protección natural, mientras tanto por lado norte la topografía posee una ligera inclinación permitiendo un fácil acceso, asimismo en sus extremos este y oeste el terreno es ligeramente inclinada.

Posee aproximadamente cuatrocientos cincuenta (450) unidades arquitectónicas de planta circular, de diversos tamaños que obedece a un patrón local, distribuidas 
de manera agrupada, en algunos casos sin separaciones de modo concatenado. En la parte alta la topografía del terreno es ligeramente plano, sobre la cual van distribuidas las unidades arquitectónicas con un orden del tipo vivienda - patio (alveolar). El flanco sur es bastante accidentado (inclinada), por lo cual los chukurpus previamente acondicionaron terrazas artificiales, obteniendo un terreno horizontal, de tal manera que van ascendiendo y tomando una forma escalonada. Sobre estos se erigieron las viviendas que se abren a pequeños patios semicirculares que incluyen en su interior cistas pequeñas, las estructuras muestran cierta inclinación hacia el interior. Asimismo aprovecharon el espacio al máximo creando accesos escalonados y pasadizos que interconectan a cada unidad alveolar con un camino principal que cruza el sitio de este a oeste, este a su vez nos lleva a una única plaza irregular ubicada en la cima del sitio (ver figura 02).

\subsection{Sectores}

El sitio arqueológico se ha sectorizado tomando en consideración la funcionalidad, en dos sectores muy bien definidos:

\section{Sector I}

Está ubicado sobre un promontorio natural, al oeste del anexo de Villa Alta, donde se puede apreciar un conjunto de recintos circulares de manera dispersa, que van
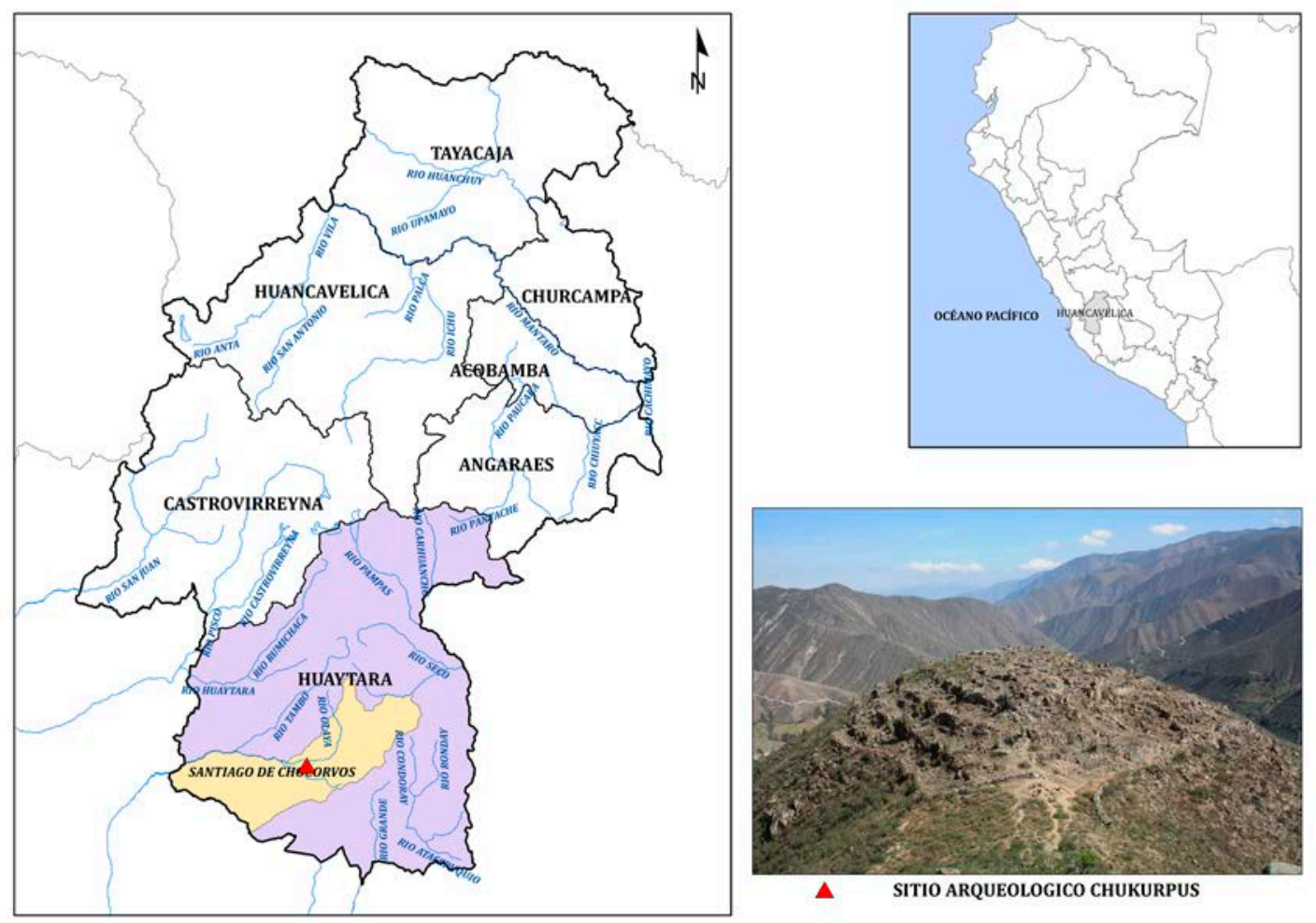

Figura. 02. Mapa de ubicación del sitio arqueológico Chukurpus en el drenaje superior del río Ica. (Elaborado por Marco A. Taquiri). 
ascendiendo desde la parte baja hasta llegar a la cima que presenta una plaza aterrazada. La plaza está organizada de pequeños recintos cuadrangulares de piedra labrada, que correspondería a la ocupación inca. Por el momento no se han realizado excavaciones en estas estructuras. La plaza ocupa un espacio dominante, existe una escalinata que conduce directamente a este lugar, posiblemente haya sido utilizado con fines ceremoniales en ambos periodos.

\section{Sector II}

Está ubicado sobre un promontorio natural al este del anexo de Miraflores, está dividido del primer sector por un declive natural. En este sector se puede observar algunos de los componentes en buen estado de conservación, presenta una densa distribución de recintos circulares tanto en la parte alta como en la ladera, que se interconectan por un pasadizo principal que se encuentra en la parte central y que se dirige de este a oeste. En este sector se ejecutaron las excavaciones arqueológicas, una de las cuadriculas fue ubicado en la parte baja, mientras tanto las tres restantes están ubicadas en la parte alta, al interior y exteriores de los espacios circulares (ver figura 03 y 04).

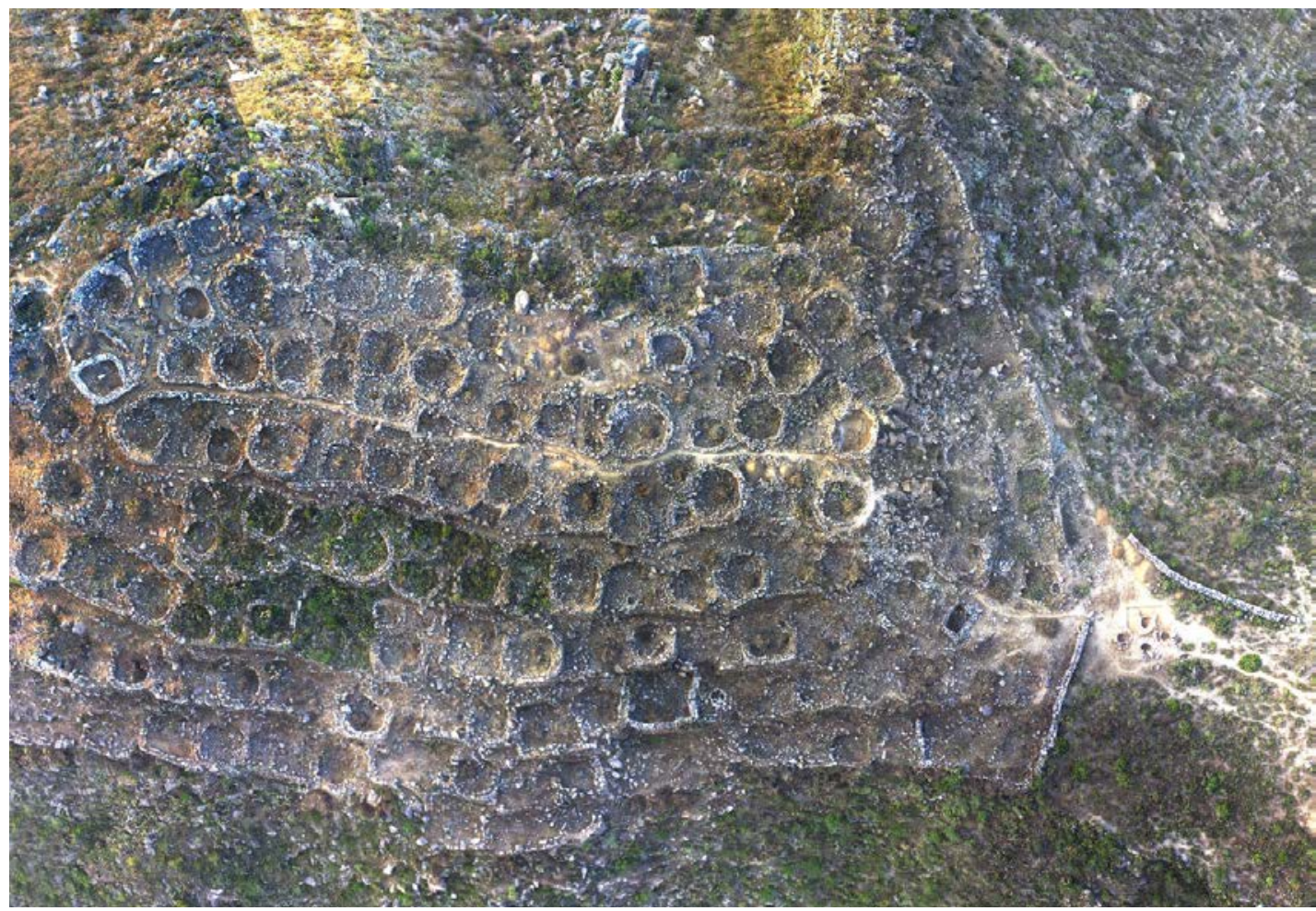

Figura 03. Vista panorámica de la distribución de las unidades arquitectónicas en el sector II del sitio de Chukurpus. Foto: Carls Chuquihuaccha, 2019. 


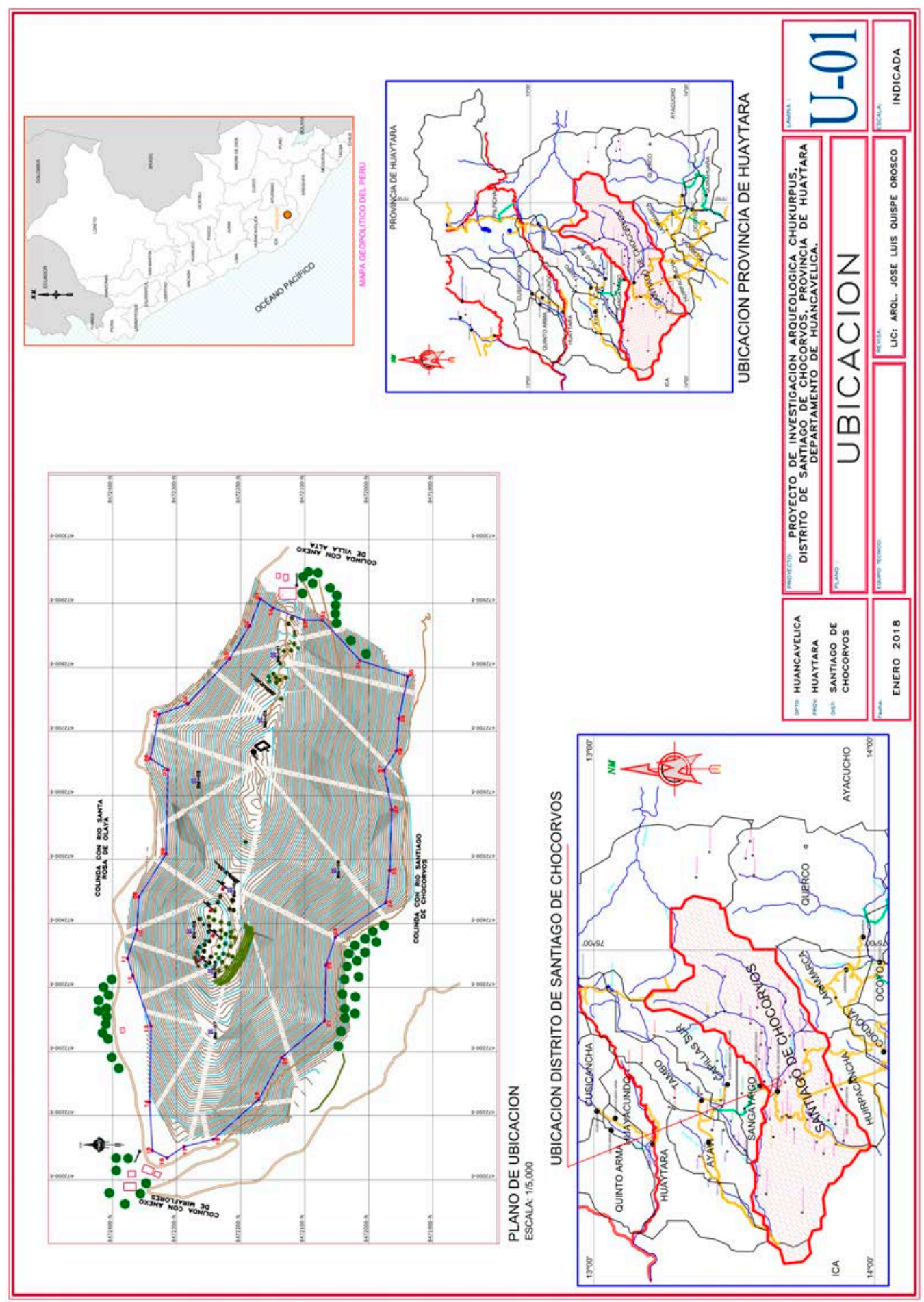

Figura 04. Plano de sectorización y distribución arquitectónica de Chukurpus. (Elaborado por José L. Quispe) 


\section{EXCAVACIONES EN CHUKURPUS}

Se realizaron excavaciones arqueológicas en cuatro (04) unidades, en lugares estratégicos del sector II. La unidad de excavación 01 fue ubicado en la parte baja del sector II, cubre un espacio de chullpas concatenadas. Las unidades 02, 03 y 04 se disponen en la cima del sector II, ubicados arbitrariamente dentro de edificios circulares (unidad 02 y 04), en un espacio abierto con diversos componentes arquitectónicos (unidad 03) (ver figura 05).

\section{Unidad 02}

Ubicación: La unidad de excavación 02 se ubicó en la cima del sector B, al interior de un recinto circular de 5 metros de diámetro. Se excavó un cuadrante de 4 x 4 metros con un área total de $16 \mathrm{~m}^{2}$. En la unidad 02, el perfil reveló cuatro capas estratigráficas: S (Superficial), A, B y C (ver figura 06).

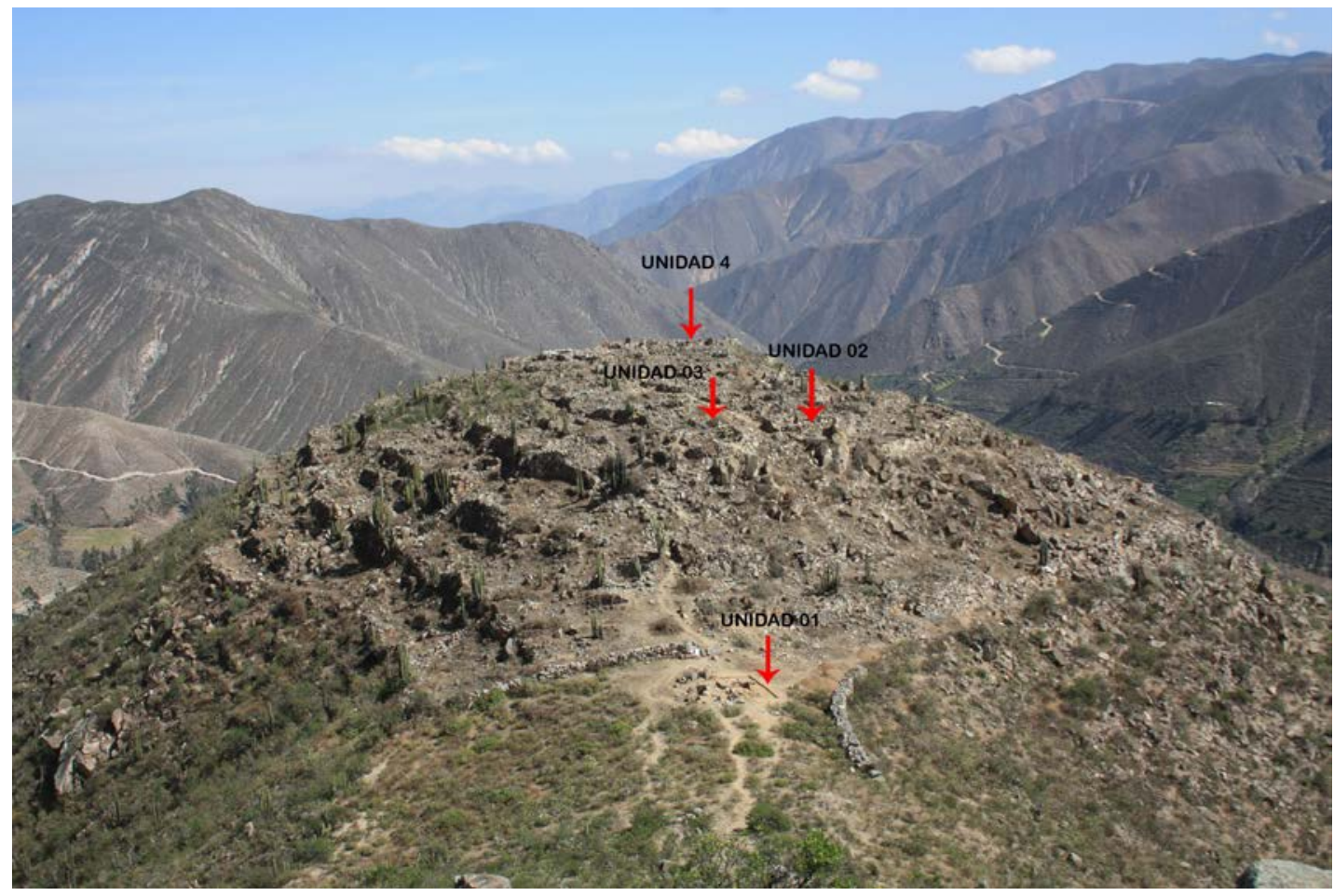

Figura 05. Sector II de Chukurpus y ubicación de las unidades de excavación. Foto: José L. Quispe.

2. Las viviendas (unidad 02 y 04) y los patios abiertos (unidad 03), son dos elementos arquitectónicos que forman una composición particular para el Período Intermedio Tardío, denominadas unidades alveolares. (Lavalle y Julien, 1897). Los materiales inca aparecen en tres unidades (02, 03 y 04), en la unidad 01 no aparecen materiales Tawantinsuyu por lo cual no se ha tomado en cuenta para la elaboración de este artículo. 

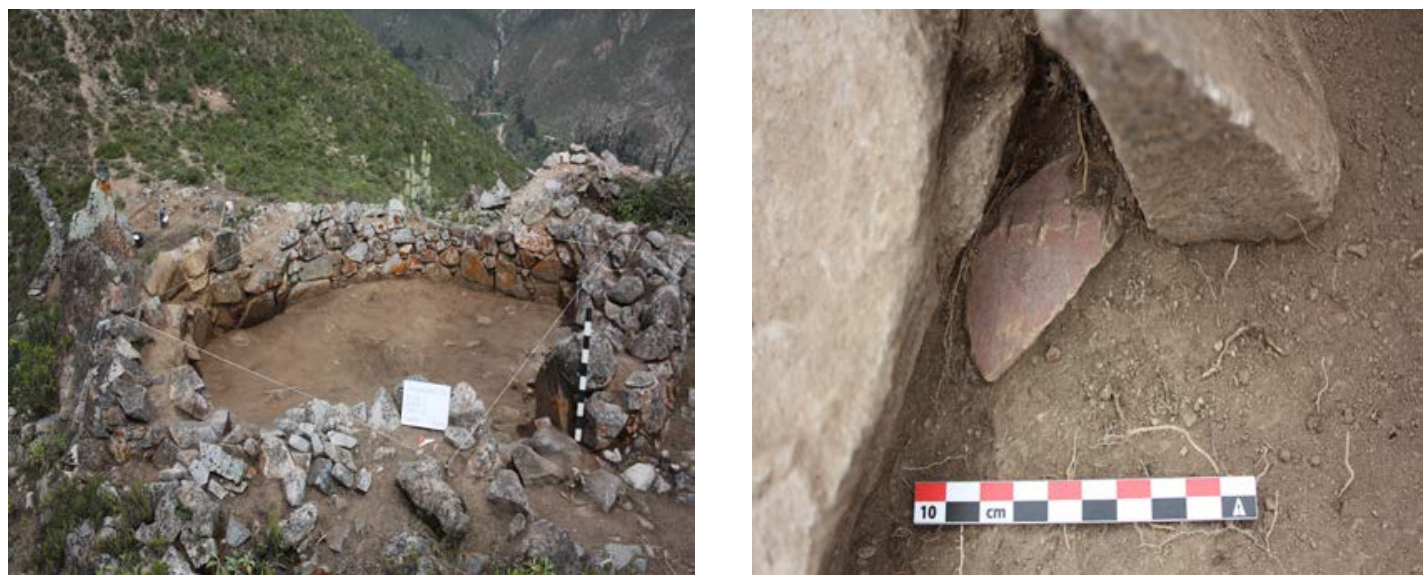

Figura 06. Planta de la unidad 02. Exposición de la capa A y fragmento de gollete de jarra con incisiones (arqalla-PIT) y engobe violáceo (inka). Foto de Marco A. Taquiri.

CAPA S: Estrato geológico formado por la constante acumulación de material orgánico.

CAPA A: Relleno intencional de $25 \mathrm{~cm}$ cubre la totalidad del recinto y corresponde al constan. Sobre la capa se ubicó restos de un empedrado que contiene entre los resquicios fragmentos de cerámica del Horizonte Tardío. Un fragmento corresponde a una jarra, presenta aplicaciones del estilo arqalla y buen tratamiento de superficie de probable influencia inca. Este material representa una clara evidencia para determinar cambios entre el Intermedio Tardío y el Horizonte Tardío.

CAPA B: Apisonado de barro que cubre la totalidad de los resquicios de la roca estéril (capa C). Sobre esta se encontró un fragmento de asa de aríbalo inca provincial.

CAPA C: Esta capa corresponde a un labrado intencional sobre la roca estéril y representa la ocupación más temprana del recinto. Al centro del recinto se encontró un fogón y abundante cerámica con muestras de quema, producto de la combustión, que significó restos de una actividad doméstica relacionado con la preparación de alimentos.

\section{Unidad 03}

Ubicación: La unidad de excavación 03 se ubicó en la cima del sector B. Se excavó un cuadrante de $4 \times 4$ metros con un área de $16 \mathrm{~m}^{2}$. Estas medidas conforman parte de varias estructuras tales como: Un patio ubicado al lado sur; un pasadizo en la parte central; una estructura circular al lado norte y otro patio al este; además de una cista semi circular ubicada en la esquina sureste de la unidad. La excavación en el patio sur ha revelado material cerámico del Horizonte Tardío (ver figura 07). 


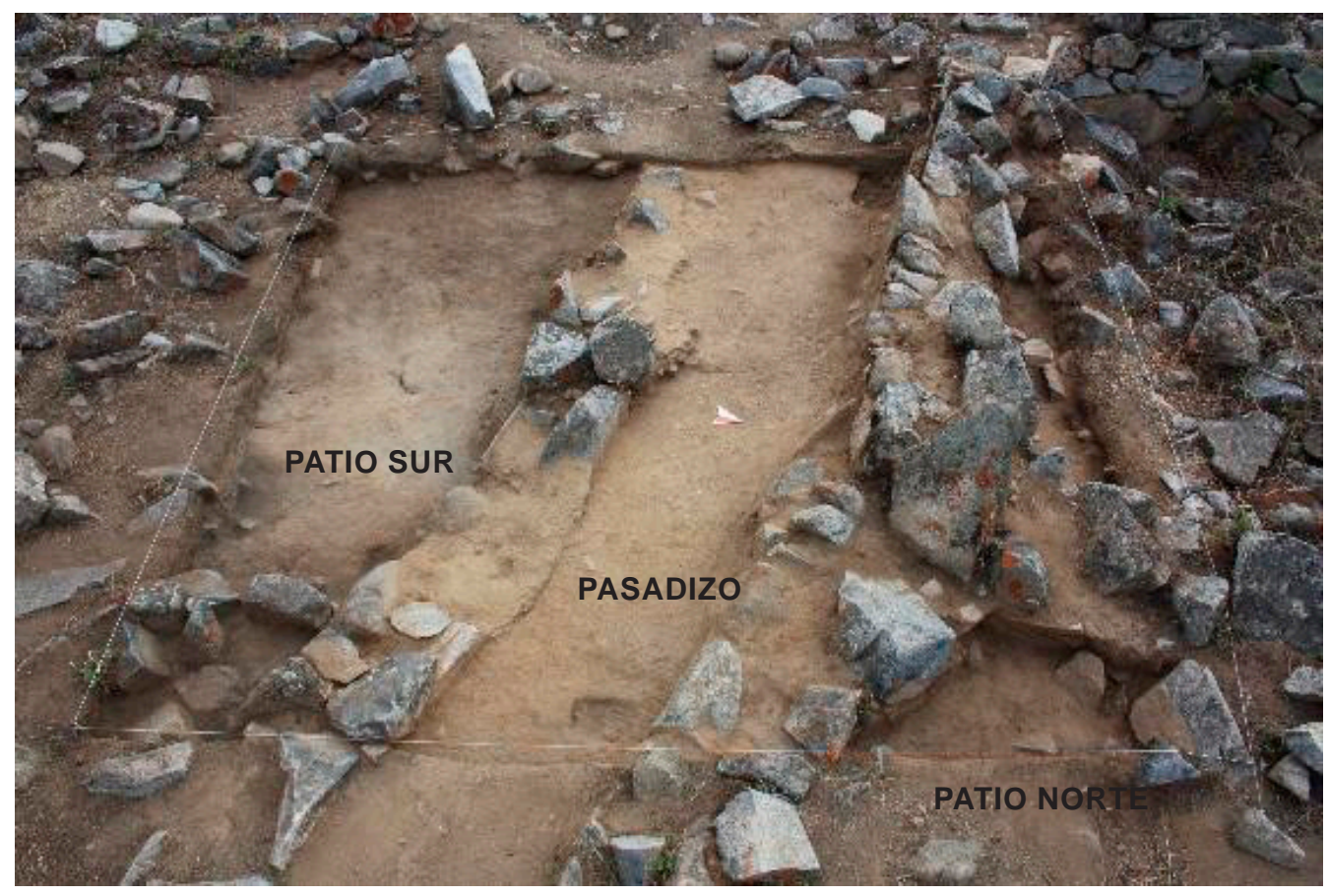

Figura 07. Planta de la unidad 03. Exposición de la capa A y la distribución de los espacios. Foto de José L. Quispe.

\section{Patio Sur}

La excavación de esta estructura reveló cuatro estratigráficas: S (Superficial), A, B y C (ver figura 08 y 09).

CAPA S: Estrato geológico formado por la constante acumulación de material orgánico.

CAPA A: Relleno de tierra compacta de $20 \mathrm{~cm}$, en promedio. Al interior de esta acumulación se encontró dos fragmentos de escudilla inca provincial.

CAPA B: Relleno de tierra de $20 \mathrm{~cm}$, en promedio. Se registró material cultural correspondiente a fragmentos de cántaro que presentan diseños con representación de bandas y franjas horizontales en color crema, negro y rojo violáceo.

CAPA C: Esta capa corresponde a la roca estéril y representa la ocupación más temprana del patio.

\section{Unidad 04}

Ubicación: La unidad de excavación 04 se ubicó en la cima del sector B, al interior de un recinto circular de 5 metros de diámetro. Se excavó un cuadrante de 4 x 4 metros, además de una ampliación al oeste de $1 \mathrm{~m}$ (figura 10). 


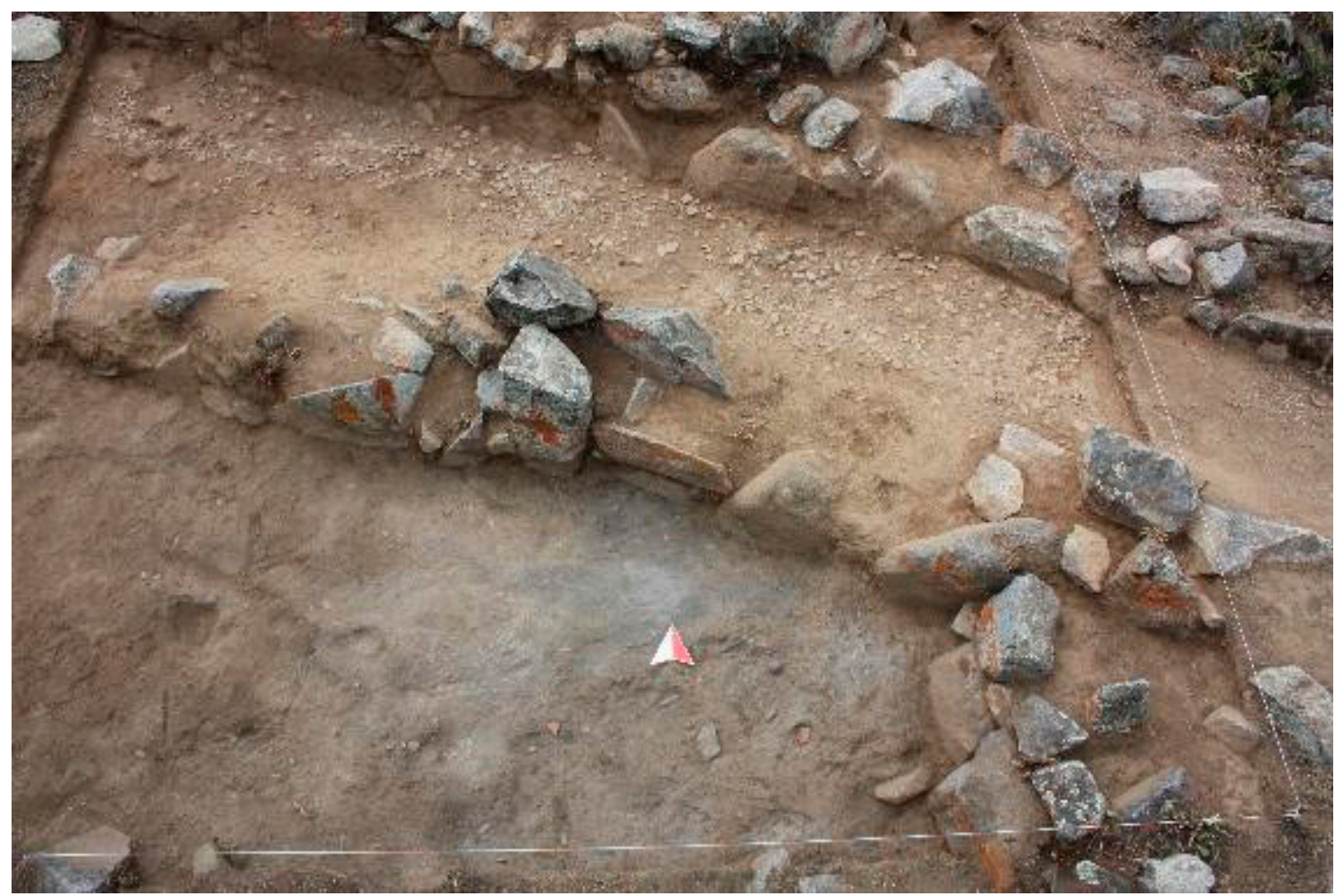

Figura 08. Exposición de la capa A. Unidad 03 - Patio Sur. Foto de José L. Quispe.
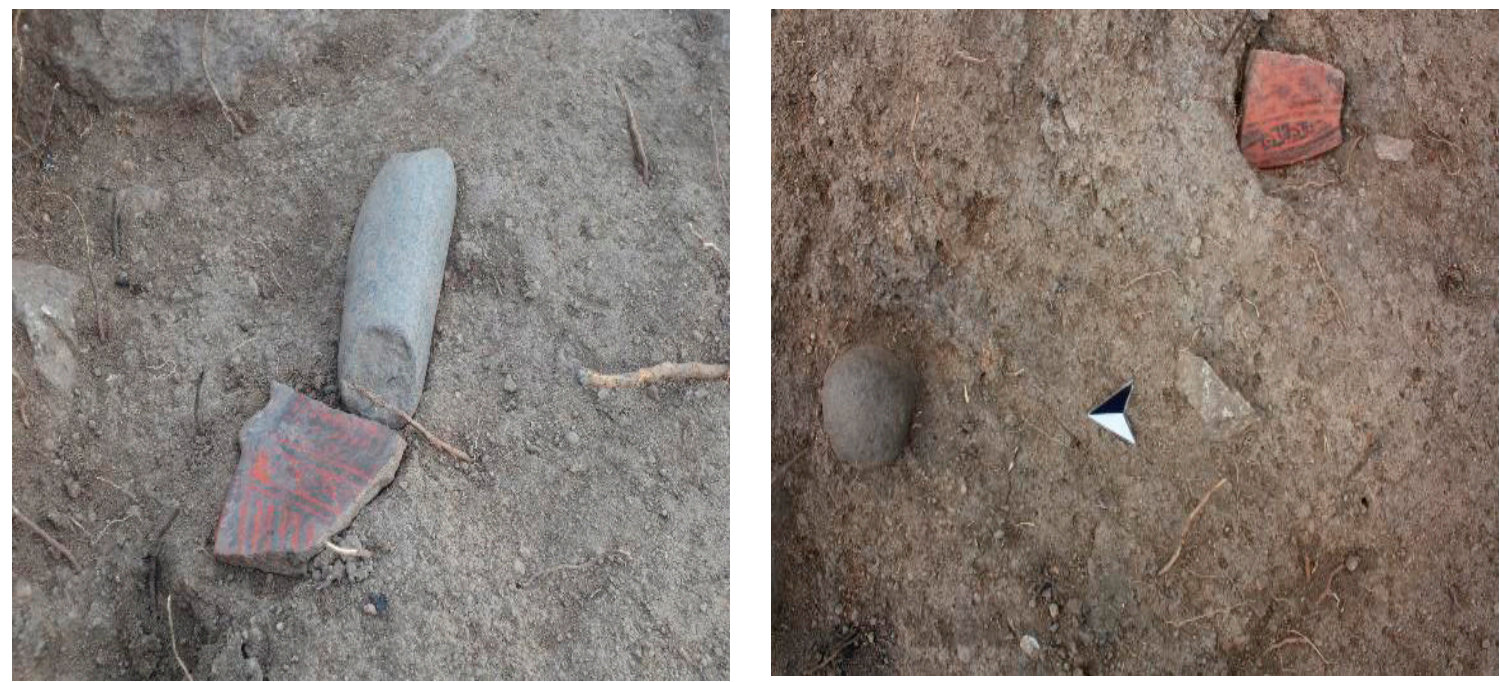

Figura 09. Fragmentos de escudilla inka provincial, asociados a un percutor y proyectil. Patio Sur: Unidad 03 - Capa A. Foto de José L. Quispe. 

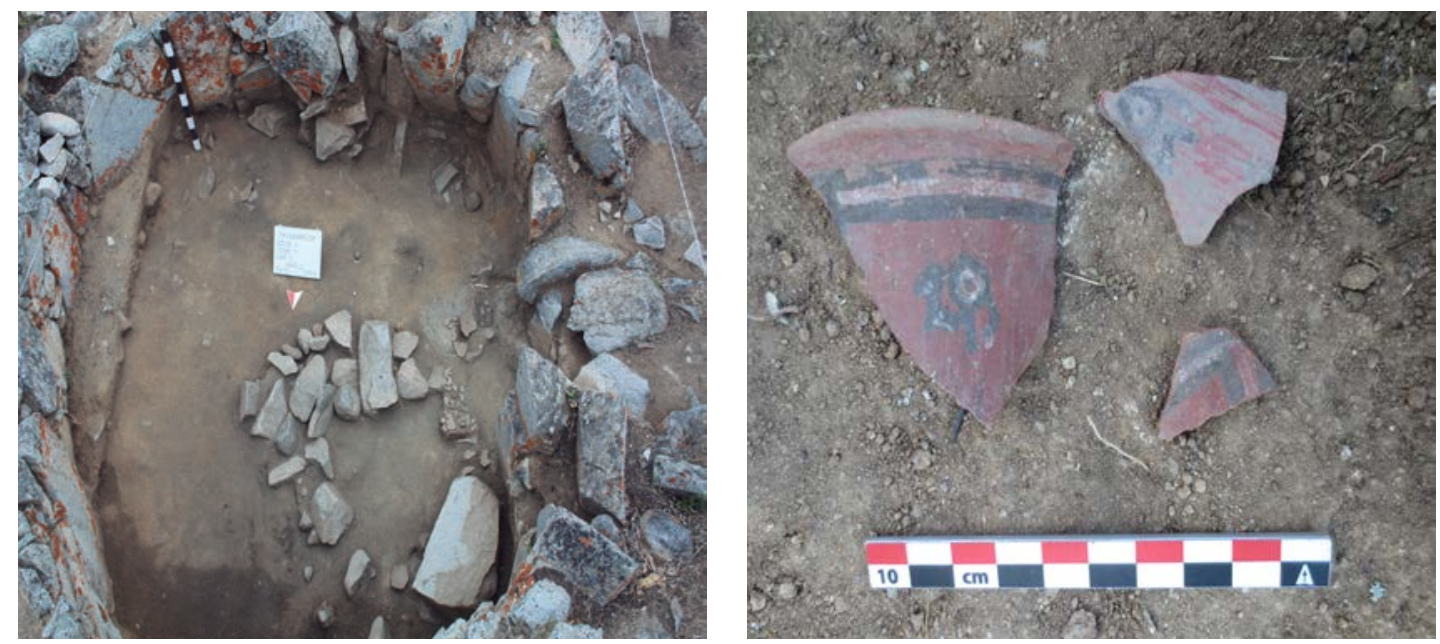

Figura. 10. Planta de la unidad 04. Exposición de la capa A y fragmentos de vaso ica-inca (Ica 9). Foto de Marco Taquiri.

El perfil de excavación reveló tres capas estratigráficas: S (Superficial), A y B.

CAPA S: Estrato geológico, contiene material orgánico o top soil.

CAPA A: Relleno intencional de 25 a $30 \mathrm{~cm}$, cubre la totalidad del recinto y corresponde al material acumulado por la constante ocupación del edificio a través de los años. Al interior de esta capa se encontró pequeños fragmentos de un vaso ica - inca.

CAPA B: Esta capa corresponde a un labrado de la roca tipo arenisca para crear el piso que representa la ocupación más temprana del recinto. Al centro del recinto se encontró una considerable cantidad de ceniza acumulada, todo indica que un fogón se ubicaba al centro del recinto. Sobre este piso se encontró gran cantidad hallazgos, entre ellos: batanes y morteros con sus respectivos moledores, así como ruecas y ajustadores de hilo o choqches elaborados de asta de cérvido y un pequeños fragmentos de cerámica inca.

\section{LA CERÁMICA INCA PROVINCIAL DE CHUKURPUS}

En Chukurpus, la excavación del patio sur de la unidad 3 reveló varios fragmentos que de acuerdo a la reconstrucción en el laboratorio corresponden a una pieza de escudilla del periodo tawantinsuyu. De acuerdo a la clasificación de Meyers (1975) ${ }^{3}$, esta pieza se trata de una escudilla de estilo inca provincial. La forma de la escudilla encontrada, está relacionada con la Forma 13 (F 13) de la clasificación de Meyers

\footnotetext{
3. De acuerdo a la clasificación de Meyers (1975, p. 9) la cerámica inca provincial se define como: «Cerámica autóctona de las provincias fabricada bajo la dominación incaica». Con relación a las formas de cerámica del estilo inca cusco, Meyers (1975, p. 10) considera ocho clases de cerámica con 14 formas especiales, de las cuales la escudilla que se encontró en Chukurpus corresponde a una variante de la Forma "F": Platos y escudillas.
} 
(1975). Así mismo, Ravines (2011) lo identifica como una "variante" de la Forma 13 (F 13); por lo cual, la escudilla del PIA Chukurpus se relaciona con la variante "c" de la clasificación de Ravines.

El diseño y los motivos decorativos geométricos (estilo), las figuras de aves estilizadas (iconografía), la pasta fina oxidante y el engobe rojizo de la escudilla, se pueden identificar con la alfarería inca y nos indican una procedencia provincial de la vajilla (ver Figura 10). La escudilla ha sido identificada por Betanzos (1880 [1551], p. 124) como parte de un "proveimiento" necesario de las fiestas y sacrificios que realizaba el Inca: «E [y] con cada dos destos enterraban mucho servicio de oro y plata, como eran platos y escudillas y cantaros, ollas y vasos para beber». La política imperial de anexiones demandaba el intercambio de bienes y objetos, la cooptación diplomática de una élite local en Chukurpus podría requerir el intercambio de estos objetos imperiales, en el marco de reciprocidades a nivel local y regional (figura 11).

\section{DISCUSIÓN}

Las investigaciones arqueológicas en Chukurpus han demostrado la presencia inca en la cuenca alta del río Ica. La presencia de material cerámico del Horizonte Tardío ha permitido evaluar la intensidad de estas ocupaciones. Durante el Período Intermedio Tardío la mayoría de sitios arqueológicos ocupan las partes altas, especialmente cumbres elevadas. Chukurpus presenta estas características: La arquitectura está conformado por edificios circulares agrupados en patios, algunos de ellos están construidas sobre terrazas artificiales. La excavación de una vivienda (unidad 02) ha revelado un nivel de ocupación que corresponde al Horizonte Tardío, se trata de restos de un empedrado con pequeños fragmentos de cerámica pertenecientes a este periodo, aunque no es posible determinar claramente las características de estas cerámicas, un fragmento que pertenece a una jarra presenta incisiones en el gollete, estas incisiones nos recuerdan remanentes del estilo arqalla del Periodo Intermedio Tardío, aunque la superficie violácea indica un mejor tratamiento, esta vajilla es de probable influencia inca fabricado por alfareros locales ${ }^{4}$.

Sin embargo, no es posible definir claramente la ocupación inca en Chukurpus, los materiales escasos no son suficientes para delimitar este período. Al no contar con más indicadores, la interpretación nos acerca a la presencia de elementos intrusivos inca, tal como sucede en el patio sur de la unidad 3. Al interior de una acumulación de ceniza (inclusión en la capa A) se registró dos fragmentos de escudilla inca

4. El estilo arqalla es el material cerámico de uso común emparentado con las etnias de la Confederación Chanka posteriormente anexados al Imperio inca. Este grupo alfarero está asociado a los poblados edificados en lugares estratégicos que presentan un patrón de asentamiento de viviendas-patio, que forman unidades alveolares; geográficamente de amplia dispersión en Huancavelica, Ayacucho y parte de Apurímac (González Carré et at., 1987, p. 67-68; Urrutia, 2014, p. 26; Valdez, 2002, p. 406). 

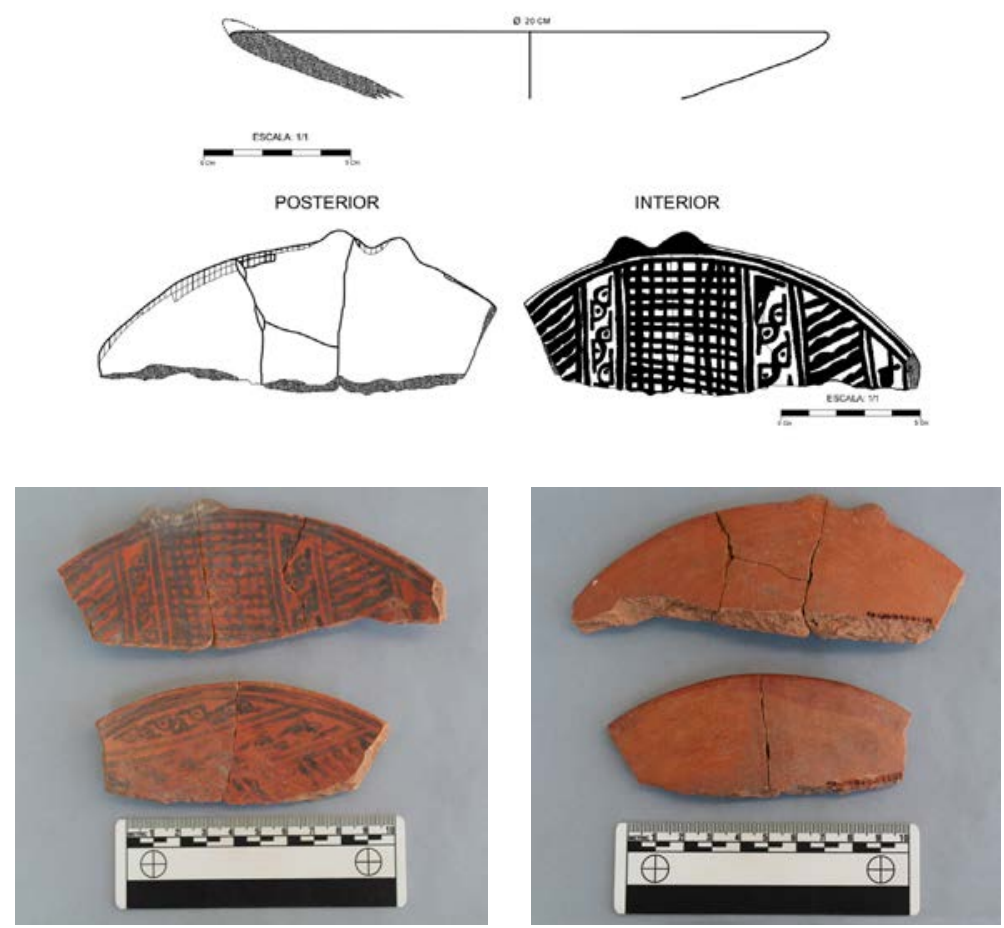

Figura 11. Fragmentos de escudilla inka provincial que aparecen en el relleno (Capa A) del Patio Sur (Unidad 03). Foto y elaboración de José L. Quispe.

provincial con diseños geométricos y animales ornitomorfos estilizados (colibrí). La acumulación de ceniza corresponde a un relleno traído intencionalmente desde otro espacio y depositado en este lugar, no hay evidencia de que fuese quemado in situ, ya que los materiales asociados como los fragmentos de cerámica y los líticos no evidencian huellas de quema.

También sobre el piso labrado de la vivienda excavada (unidad 02), se encontró un asa de aríbalo, este pequeño ejemplar muestra atributos del estilo inca con decoraciones de líneas de color negro que separan bandas de color crema y rojo indio. Cabe indicar que no existe una estratigrafía definida que nos permita determinar una secuencia. La compactación (Capa A) que cubre el piso original del recinto apenas sobrepasa los $20 \mathrm{~cm}$, pensamos que corresponde a una acumulación periódica y en constante resanamiento, y remodelación del piso de vivienda. A pesar de las limitaciones, estos materiales han permitido estimar la inédita presencia inca en el lugar. Las principales líneas de evidencia utilizadas para evaluar esta presencia son: Cambios en el estilo cerámico local (fragmento de jarra del estilo arqalla e inca) ${ }^{5}$,

5. Esta forma distintiva de jarra con gollete inciso derivada de los antecedentes arqalla experimentó un cambio estilístico en el tiempo, es probable que en el Horizonte Tardío este tipo de vasija de fabricación local haya sido influenciado por la técnica inca para un mejor acabado. Estos detalles nos permite distinguir cambios entre el Período Intermedio Tardío y el Horizonte Tardío. 
la presencia de artefactos incas (fragmentos de asa de aríbalo y escudilla inca); y la continuidad de la arquitectura local en el Horizonte Tardío.

Sobre el piso labrado de otra vivienda (unidad 04), la excavación reveló reducidos fragmentos de cerámica, que reconstruidos forman un vaso perteneciente al estilo ica-inca del Horizonte Tardío (Ica 9). Este estilo fue definido por Menzel (1976) y corresponde a la cerámica provincial del valle de Ica del Horizonte Tardío que representa la continuidad de la tradición local ica con influencia de formas y motivos imperiales.

A partir de las fuentes etnohistóricas se tiene claro que antes de la conquista inca, la transecta occidental entre las regiones de Ica, Ayacucho y Huancavelica fue un territorio dinámico habitado por distintos grupos sociopolíticos: Lurin ica, yauyos, chocorbos y rukanas. En este sentido, el sitio de investigación Chukurpus, por su ubicación, podría caer dentro del patrón multiétnico de poblados periféricos chukurpus establecidos en la cuenca alta del río Ica, tal como sucede en el patrón andino de control territorial disperso, las regiones periféricas al centro principal estaban ocupados simultáneamente por diversas etnias (Murra, 1975).

Estas regiones periféricas, pueden considerarse contiguas a la ocupación principal de los grupos yungas lurin ica del valle de Ica. Posteriormente, esta región fue anexada bajo las políticas persuasivas del Tawantinsuyu. La evidencia de cerámica ica-inca (Ica 9) en el sitio Chukurpus, evidenciaría la interacción y movilidad de estos grupos étnicos durante el Horizonte Tardío (figura 12).

No existen cambios sustanciales en la cultura material local correlacionada con la presencia inca, parece que los edificios circulares chukurpus encontrados en el área que tienden a tener diámetros que van de 5 a $6 \mathrm{~m}$ no han sufrido innovaciones en el Horizonte Tardío, no encontramos ejemplos de la arquitectura inca que influya en los estilos de construcción locales, tal como sucede en algunos sitios del sur de Ayacucho que incluyen edificios circulares significativamente grandes con un diámetro de 7 a $10 \mathrm{~m}$, visible en el valle del río Chicha-Soras y Sondondo que presentan elementos arquitectónicos inca como en Chiqna Jota (Meddens y Schereiber, 2010); y en ocasiones son aún más grandes, como Naupallacta en la cuenca alta del río Acarí (Taquiri y Mendoza 2018) ${ }^{6}$.

El poblado Chukurpus fue un núcleo importante en el Período Intermedio Tardío y posiblemente haya desempeñado el papel de foco de poblamiento principal bajo el dominio inca. Stern (1986, p. 49) afirma que antes de que el Inca llegara a los Angaraes, cada pueblo tenía su propio curaca o señor y que había mucha guerra entre

6. La cuenca alta de los ríos Acarí y Nasca, y el valle de Sondondo fueron ocupados por la macroetnia rukana (Monzón 1881 [1586]). La ocupación inca del sur de Ayacucho es bastante notable y los incas pusieron estos territorios bajo su control. Casi todos los sitios importantes cuentan con arquitectura inca (Incahuasi de Parinacochas, Pulapuco de Lucanas), así como elementos de la infraestructura inca, incluidos centros de almacenamiento, ushnus de altura, el camino inca de unión a los llanos - que conectaba Hatun Soras con Paredones, Nasca- y un puente colgante en Aucará (Cavero 2010; Meddens y Schereiber 2010). 
ellos. Postulamos la hipótesis de que un señor Inca, probablemente un tucuyricu, un supervisor regional de sangre real estaba destinado en los ckukurpus para administrar la región y hacer que la gente cumpliera con las órdenes imperiales ${ }^{7}$. Los artefactos incas son bastante sorprendentes en los contextos domésticos, esto nos indica que no existe una diferenciación jerárquica de arquitectura destinada a la elite, tal como sucede por ejemplo en el valle de Jauja (D’altroy, 2015, p. 142). Además no descartamos que sus residentes fueran llevados al territorio de los chukurpus como mitimaes. Dado que este lado del valle de Ica habitado por hablantes aimaras puede haber sido ocupado por hablantes quechuas producto de la inserción de mitimaes (Cerrón-Palomino, 2004, p. 10). Este sitio podría tener indicios de una política inca de reasentamiento, sabemos por ejemplo, que los pueblos étnicos chankas, guaros y caxamarcas habían sido reasentados en la región de los Angaraes en Huancavelica durante tiempos de los incas (ver tabla 1). La política de reasentamiento de miti-
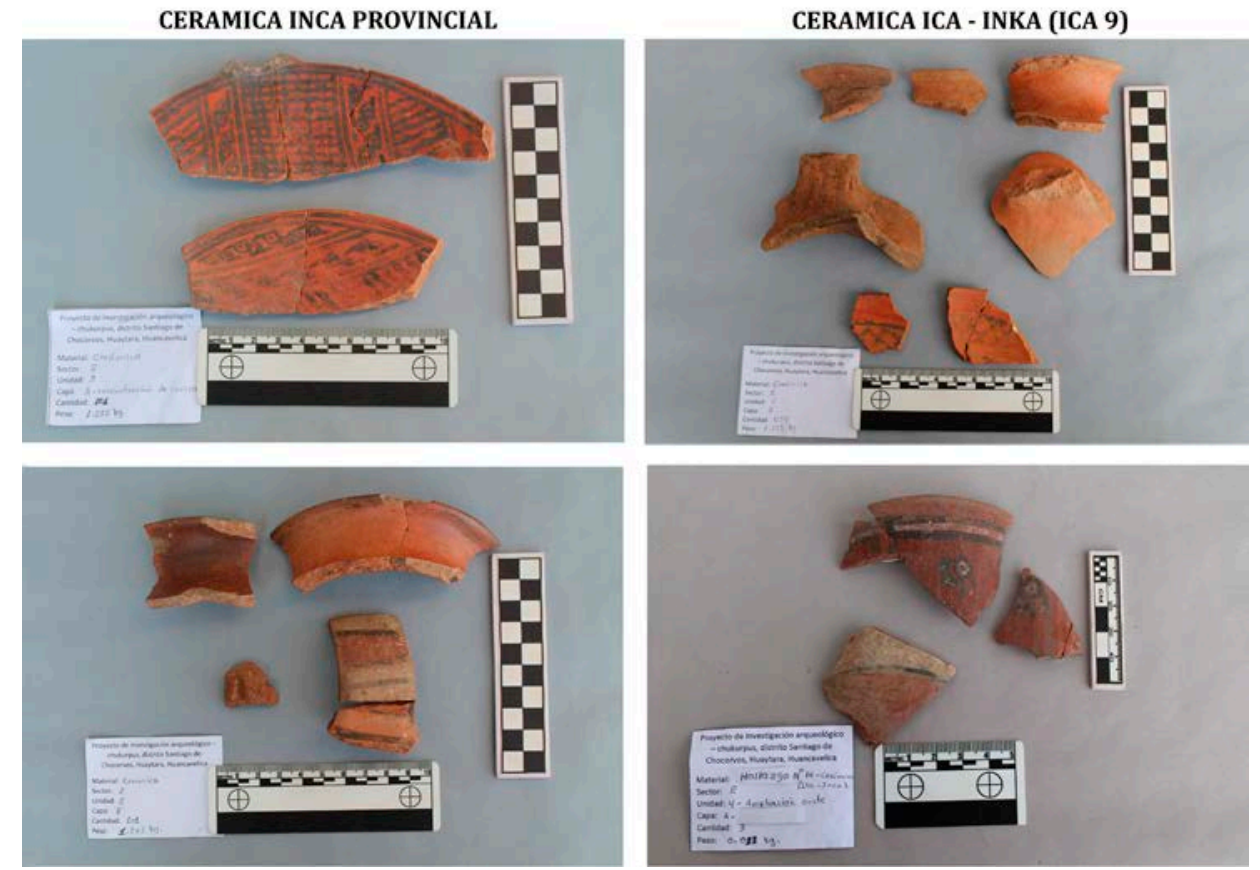

Figura. 12. Fragmentos de cerámica del Horizonte Tardío en Chukurpus. Inca provincial (izquierda) ica - inka (Ica 9) (derecha). Foto de José L. Quispe.

\footnotetext{
7. Betanzos (1880[1551], p. 74) indica que Pachacutec ordenó a los curacas conquistados que proporcionaran un recuento veraz de lo que estaba disponible en sus tierras y lo que podría ser producido. Un señor Inca sería colocado en cada provincia para vigilar las cosas. Los curacas enviaron por quipus y pinturas para documentar los recursos en sus provincias. Luego, los incas nombraron a los señores incas que vivirían en cada provincia para llevar un registro de las cosas y reorganizar la distribución de las tierras: "El inca Yupaqui [Pachacutec] mando a los señores caciques que allí estaban, que le trajesen por cuenta cada uno de ellos los indios que allí consigo tenían, y luego los señores caciques le trajeron por quipo, que dice cuenta, la suma de los indios que tenían; y sabido por el Inca Yupanqui los indios que había, mando a los señores que luego los repartiesen y ansi fue hecho". Cuando todo se resolvió, los curacas partieron hacia sus provincias llevándose consigo a sus señores incas.
} 
maes especializados en nuevas zonas configuró un mar multiétnico, la presencia de grupos distantes nos indica con nitidez las consecuencias de las políticas de disturbación étnica hecha por los cuzqueños en la región ${ }^{8}$.

\section{CONCLUSIONES}

Si bien la evidencia de la ocupación inca en Chukurpus no es clara, hay indicios de una importante presencia inca, aquí, y en las inmediaciones. Con base en evidencia documental, junto con datos arqueológicos limitados, sugerimos que Chukurpus fue un asentamiento importante del Período Intermedio Tardío, que más tarde cayó bajo el control Inca. La evidencia documental indica claramente que los chukurpus no resistieron activamente la conquista Inca, esto debería llevarnos a esperar un trato diferente por parte de los incas. Los restos arquitectónicos sobrevivientes son típicos de las etnias tardías y no hay indicios de haber sido influenciados por los incas, tanto la cerámica importada de estilo inca provincial como las imitaciones locales del estilo inca son frecuentes y aparecen como material intruso en los niveles domésticos.

El paisaje de la cuenca muestra claramente el papel que jugó durante el Horizonte Tardío. Las laderas de los ríos Olaya y Santiago han sido amplia y densamente aterrazados para maximizar la productividad agrícola. Con la presencia de la administración cuzqueña las laderas más marginales parecen haber entrado en producción y los sistemas de riego se usaban cada vez más como parte del sistema agrícola. Sin embargo, no hay evidencia clara de la incorporación de la región al Imperio inca y quizá el mejor ejemplo de la arquitectura inca presente en el sitio es la plataforma aterrazada y estructuras rectangulares erigidos con muros de piedra moderadamente bien labrados en el Sector 1, el probable ushnu inca podría simbolizar su autoridad sobre esta región (figura 13). Si para consolidar y mantener su dominio de la región, los incas desmantelaron las estructuras locales e impusieron estructuras de poder en una forma de control relativamente directa, esta plazoleta sería una clara evidencia de este tipo de control, las futuras excavaciones en este sector nos aclararan las estrategias de control y los efectos de la presencia inca en Chukurpus.

Agradecimientos: Este artículo ha sido elaborado en colaboración del equipo de arqueólogos del PIA CHUKURPUS, entre ellos: Rolando Quispe (UNSCH), Alex Huamaní (UNICA) y Yurisan Aparicio (UNICA). También agradecemos a la Revista del Museo de Arqueología y Antropología UNMSM por permitirnos publicar este tra-

8. Sobre las consideraciones etnohistóricas de los mitimaes se ha revisado documentos y litigios coloniales. En el caso del Mantaro, los cayambis procedentes del norte fueron trasladados a Matipampa-Huanta, tierra de cocales sobre la margen derecha del río Mantaro (Espinoza Soriano, 2011). Los chillques ocupaban los valles interandinos del grupo étnico rukana (Salas, 2014). Los orejones antas, incas de privilegio fundaron Huamanguilla, cerca de la actual Huamanga (Santillana 1979). En la cuenca del Caracha-Pampas, sur de Ayacucho, las etnias del valle del Mantaro (huancas y xauxas) fueron ubicados en la zona quechua (Carbajal 1881 [1586]). El desplazamiento demográfico en el territorio de los angares y chukurpus está documentado, estos grupos originarios fueron masivamente deportados y reemplazados por mitmas traídos de lejanos territorios, generalmente chankas y cajamarcas. 


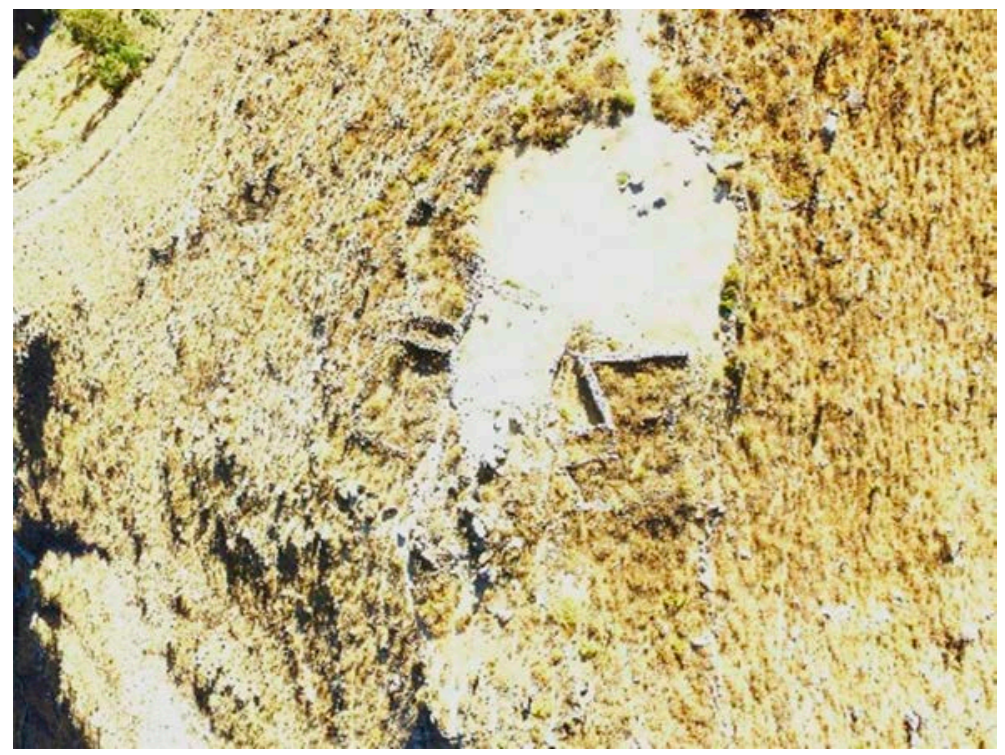

Figura. 13. Plataforma y estructuras rectangulares de piedra labrada en el Sector 1, el probable ushnu podría simbolizar la autoridad inca en Chukurpus. Foto aérea de José L. Quispe.

bajo y a la Junta Directiva de la Comunidad campesina de Villa Alta, Miraflores y Santiago de Chocorvos por las facilidades brindadas en la investigación.

\section{REFERENCIAS BIBLIOGRÁFICAS}

de la Bandera, D. (1968). Relación del origen e gobierno que los Ingas tuvieron. Biblioteca Peruana. Tomo 3 (pp. 491-510). Editores Técnicos Asociados. Lima. (Original publicado en 1557).

Bauer, B., Araoz, M. y Kellett, L. (2013). Los Chankas. Investigaciones Arqueológicas en Andahuaylas (Apurímac, Perú). Instituto Francés de Estudios Andinos. Lima.

de Betanzos, Juan. (1880). Relación de Antiguedades deste Reyno del Piru. (Original publicado en 1551). Instituto Francés de Estudios Andinos. Lima.

Carrasco, T. (2007). Angaraes. La nación de las Águilas Reales. UNMSM. Lima.

Cavero, Y. (2010). Inkapamisan: Ushnus y Santuarios Inka en Ayacucho. Mercantil Ayacucho E.I.R.L. Ayacucho.

de CarbajaL, P. (1881). Descripción de la provincia de Vilcas Guaman. En Marcos Jiménez de la Espada (Ed.). Relaciones geográficas de Indias, Perú. Tomo I, (pp. 145-168). (Original publicado en 1586).

Cerrón-Palomino, R. (2004). El aimara como lengua oficial de los Incas. Boletín de Arqueología PUCP (8), pp. 9-21.

Cieza de León, P. (1880). Crónica del Perú. Segunda Parte. En Marcos Jiménez de la Espada (Ed.). Biblioteca Hispano-Ultramarina. Madrid. (Original publicado en 1553). 
Davila Briceño, D. (1881). Descripción y Relación de la provincia de los Yauyos. En Marcos Jiménez de la Espada (Ed.). Relaciones geográficas de Indias, Perú. Tomo I, (pp. 61-78). (Original publicado en 1586).

D'altroy, T. (2015). El poder provincial en el imperio inka. IEP Instituto de Estudios Peruanos. Lima.

Duviols, P. (1967). Un inédit de Cristóbal de Albornoz: La instrucción para descubrir todas las guacas del Pirú y sus camayos y haziendas. Journal de la Société des Américanistes. Tomo 56(1), 7-39.

Espinoza Soriano, W. (2011). La coca de los mitmas cayampis en el reino de Ancara. Siglo XVI. Industrial Gráfica San Remo S.A.C. Lima.

Garcilaso de la Vega, Inca. (1945). Comentarios Reales de los Incas. Tomo I, II y III. Emecé Editores. Buenos Aires. (Original publicado en 1609)

Gonzalez Carré, Enrique. (1992). Los Señoríos Chankas. Universidad Nacional San Cristóbal de Huamanga. Ayacucho.

Gonzalez Carré, E., Pozzi-Escot, Muriel; Pozzi-Escot, D. y Vivanco, C. (1987). Los Chankas: Cultura Material. UNSCH. Ayacucho.

Huertas, Lorenzo; Granada, Juan y González Carré, Enrique. (1976). La Revisita de los Chocorbos en 1683. UNSCH. Ayacucho.

Lavallée, D. y Julien, M. (1983). Asto: Curacazgo Prehispánico en los Andes Centrales. IEP Instituto de Estudios Peruanos. Lima.

Lane, K., Huamán, O., Coll, L., Pullen, A., Beresford-Jones, D. y French, C. (2007). De fronteras y enclaves: La presencia Nasca en la sierra de Ica. Boletín de Arqueología PUCP (22), pp. 117-132.

Lumbreras, Luis G. (1959). Sobre los Chankas. Actas y Trabajos del II Congreso Nacional de Historia del Perú, Tomo 1, (pp. 211-241).

Matos Mendieta, R. (1960). Informes sobre trabajos arqueológicos en Castrovirreyna, Huancavelica. Editorial Juan Mejía Baca. Lima.

Matos, R y Parsons, J. (1979). Poblamiento prehispánico de la cuenca del Mantaro. Arqueología Peruana (pp. 157-171). UNMSM. Lima.

Meddens, F. y Schreiber, K. (2010). Inca strategies of control: a comparison of the Inca occupations of Soras and Andamarca Lucanas. Naupa Pacha. 30(2), 127-166.

Meyers, A. (1975). Algunos problemas en la clasificación del estilo incaico. Pumapunku (8), pp. 7-25.

Menzel, D. (1976). Pottery Style and Society in Ancient Perú. Art as a Mirror of History in the Ica Valley, 1350-1570. California: University of California, Berkeley.

Murra, J. (1979). Formaciones económicas y políticas del mundo andino. Lima: Instituto de Estudios Peruanos. 
de Monzón, Luis. (1881). Descripción de la tierra del repartimiento de San Francisco de Atunrucana y Laramati. En Marcos Jiménez de la espada (Ed.). Relaciones geográficas de Indias, Perú. Tomo I (pp. 179-196). (Original publicado en 1586).

ONERN. (1976). Mapa Ecológico del Perú. Las Ocho Regiones Naturales. Lima.

Pulgar Vidal, J. (1996). Geografía del Perú. Las Ocho Regiones Naturales. Editorial Universo. Lima.

Ravines, R. (2011). Estilos de cerámica del antiguo Perú. Boletín de Lima (163), 433-564.

de Ribera, P. y de Guevara, y de Chaves, A. (1881). Relación de la Ciudad de Guamanga y sus Términos. En Marcos Jiménez de la espada (Ed.). Relaciones geográficas de Indias, Perú. Tomo I, (pp. 105-144). (Original publicado en 1586).

Rodríguez Morales, J. A. (2016). Viejas y nuevas élites: arqueología doméstica en Viejo Sangayaico, Huancavelica (1476 - 1570 d. c.). Tesis de Licenciatura. Lima, Perú: Universidad Nacional Mayor de San Marcos, Facultad de Ciencias Sociales, EAP. de Arqueología.

Ruiz Estrada, A. (1977). Arqueología de la ciudad de Huancavelica. Servicio de Artes Gráficas. Lima.

Santa Cruz Pachacuti, Juan. (1993 [1613]). Relación de Antiguedades deste Reyno del Piru. Instituto Francés de Estudios Andinos. Lima.

de Santillán, H. (1968). Relación del origen, descendencia, política y gobierno de los Incas. En Francisco Esteve Barba (Ed.). Crónicas Peruanas de Interés Indígena (pp. 97-149). Ediciones Atlas. Madrid. (Original publicado en 1563).

Salas, M. (1979). De los obrajes de Canaria y Chincheros a las comunidades indígenas de Vilcashuamán. Siglo XVI. Lima: Talleres Tipo-Offset SESATOR.

Santillana, Julián. (2012). Paisaje sagrado e ideología inca. Pontificia Universidad Católica del Perú. Fondo Editorial. Lima.

Sigminam. (2011). Ecorregiones del Perú. Ministerio del Ambiente. Lima

Stern, S. (1986). Los pueblos indígenas del Perú y el desafío de la conquista española. Huamanga hasta 1640. Alianza Editorial S.A. Madrid.

Taquiri, M. y Mendoza, A. (2010). Ñaupallacta, un poblado prehispánico de patrón local e inca. Cuenca alta del río Acarí, Ayacucho. Revista Haucaypata, 13, pp. 16-33.

Valdez, L. (2002). La alfarería de la época inka en el valle de Ayacucho, Perú. Boletín de Arqueología PUCP, 6, pp. 395-419.

Valdez, L. y Vivanco, C. (1994). Arqueología de la Cuenca del Caracha, Ayacucho, Perú. Latin American Antiquity, 5, pp. 144-157.

Urrutia, J. (2014). Aquí nada ha pasado. Huamanga, Siglos XVI-XX. IFEA Instituto Francés de Estudios Andinos. Lima. 


\section{SOBRE LOS AUTORES}

\section{José Luis Quispe Orosco}

Licenciado en Arqueología por la Universidad Nacional San Luis Gonzaga de Ica. Diplomado de Alta Especialización: Patrimonio Cultural, por la Universidad Inca Garcilaso de la Vega - Instituto Superior Peruano de Actualización y Capacitación Jurídica. Diplomado en Conservación de Objetos Arqueológicos, por el Instituto Superior de Conservación y Restauración Yachay Wasi. Diplomado en Museología, Gestión de Patrimonio y Políticas Culturales, por la Universidad Privada Simón Bolívar - Lima. Director del Proyecto de Investigación Arqueológico Chukurpus, Distrito Santiago de Chocorvos, Huaytará, Huancavelica y Director de Asuntos Académicos del Instituto de Paleontología, Arqueología y Medio Ambiente (IPAMA). Actualmente arqueólogo del Ministerio de Cultura de Ica.

\section{Marco Taquiri González}

Licenciado en Arqueología por la Universidad Nacional San Luis Gonzaga de Ica. Diplomado en Gestión del Patrimonio y de la Cultura, por la Universidad Nacional San Cristóbal de Huamanga. Diplomado en Gestión de Relaciones Comunitarias y Responsabilidad Social, por la Facultad de Ciencias Económicas de la Universidad Nacional Mayor de San Marcos. Miembro integrante del Instituto de Paleontología, Arqueología y Medio Ambiente (IPAMA). Actualmente Arqueólogo Independiente.

Ha publicado recientemente el artículo: "Ñaupallacta un poblado prehispánico de patrón local e inca. Cuenca alta del río Acarí", en la Revista Haucaypata. Investigaciones Arqueológicas del Tahuantinsuyo. Actualmente es consultor y arqueólogo independiente.

\section{Carls William Chuquihuaccha Huancahuari}

Licenciado en Arqueología por la Universidad Nacional San Luis Gonzaga. Diplomado en Metodología de la Investigación por la Escuela de Postgrado Neumann Business School. Diplomado en Derecho Administrativo y Gestión Pública por la Facultad de Ciencias Económicas de la Universidad Nacional Mayor de San Marcos. Operador-Piloto RPAS por la Dirección General de Aeronáutica Civil del Ministerio de Transportes y Comunicaciones. Actualmente presidente del Instituto de Paleontología, Arqueología y Medio Ambiente - IPAMA y director del Proyecto Arqueológico Geoglifos de Ica. 